\title{
Progress and status in wrought processing of titanium alloys
}

\author{
M. Leder ${ }^{1}$, A. Volkov ${ }^{1}$ \\ ${ }^{1}$ PSC VSMPO-AVISMA Corporation, Parkovaya st. 1, Verkhnaya Salda 624760, Russia \\ Email*, moleder@vsmpo-avisma.ru
}

\begin{abstract}
$\underline{\text { Abstract }}$
1. Introduction

All the main practical directions and methods of plastic deformation were developed in the 19th century in application for structural steels and in many respects were successfully adapted for titanium alloys taking into account their features: low thermal conductivity, high viscosity, tendency to sticking, gas saturation, hydrogen embrittlement, etc. At the moment, most of the methods: free forging, pressing, sorting and sheet rolling, drawing, etc., are very detailed for particular cases of geometries, mechanical properties and alloys classes. Manufacturers need only to optimize the processes of deformation using a reasonable choice and refinement of technological ranges, optimization of tools and workpieces, approaches to the development of the process. Despite partial repetitions and re-discoveries of already well-known progress, it did not stop, but simply moved to other levels and scales, and without becoming less interesting and succinct, although it may be, giving less ambitious results.
\end{abstract}

\section{Results and discussion}

\section{General situation}

Despite the potential threats from alternative technologies: powder technologies and additive technologies, according to [ 1 ], the forging business is growing steadily enough: $60 \%$ of surveyed companies stated growth in 2018 by $+5 \div 25 \%$, and also in the forecast of growth in 2019 year at about the same pace (Fig . 1 a). For 5 years from 2014, relative stagnation of growth was observed only on the results of 2 years: 2014 and 2017. According to the prevalence of production, titanium alloys, of course, cannot compete with carbon, alloyed and stainless steel, which produce $>50 \%$ of forging companies. But titanium alloys are comparable in prevalence with $\mathrm{Al}$ and hi temperature alloys ( Fig. 1b ), possibly due to use in the same aerospace region. In 2018, almost 20\% decrease in the number of forging companies producing titanium and hi temperature alloys, even with the normalization of the results (Fig. $1 \mathrm{c}$ ). It is difficult to reconcile with the growing market for aerospace and it is possible that this result is due to the change of the spectrum of companies of choice, or a decrease of number of players due to market globalization wrought titanium alloys .

The results of the analysis of the spectrum of problems experienced by forging companies are also very positive (Fig. 1d). On background stable topical parameters energy cost, foreign competition, and less sensitive availability of capital, raw material lead-time, raw material quality is observed growth Relevance labor shortage, higher labor costs, and in last 3 years drastically increase of raw materials costs. But all these problems fade into the background when there are orders in the market: only $14 \%$ of companies experienced a shortage of orders in 2018, despite the fact that in 2013 there were about $60 \%$.

\section{Market inquiries}

Of the 3 main market inquiries before wrought titanium companies : increase operational properties of materials, reduce lead time, cost reduction, bright cost was dominated by the dominant gain reduction. Such same old, and friend, how all wrought processing of titanium alloys . To meet this market demand, manufacturers work in the following directions: increase by - to - fly ratio , reducing the cost of batch materials , increasing the involvement of waste , reducing the cost of deformation and heat treatment, increasing the processability of the material and the efficiency of processing methods, reducing the cost of fur about working .

Taking into account the excellent work on the optimization of production costs, it is necessary to understand that the manufacturing technology of titanium semi-finished products is currently highly optimized. Further cost reduction, along with the inevitable decrease in quality, at a certain level will lead to a sharp increase in the risk of inconsistencies or negative side changes in the material $\backslash$ part properties (Fig. 2). Moreover, these discrepancies will no longer be typical, the quality management system is set up to identify and eliminate them. The unusualness of these inconsistencies can be missed by the QMS and give poorly predictable consequences of the use of such material. The critical level of risk increase is difficult to predict, as this is an unknown factor. Categorical cost reduction works as an accumulation of " explosive substances " that can " detonate " when the critical level is exceeded.

There are alternatives to reduce the cost by increasing the operational properties of the material which could not only reduce the cost, but also increase the operational characteristics of the structure.

With increasing the specific strength of the cross section of the part can be reduced, which not only leads to a decrease in cost by reducing the weight of the workpiece, but also reduces the weight of the structure - one of the most important 
performance characteristics.

At the moment, the level of the basic strength of titanium alloys can be considered the level provided by the Ti 6 AL $4 \mathrm{~V}$ alloy, which in sections over $100 \mathrm{~mm}$ can provide UTS $>1050 \mathrm{MPa}$, and in sections $<30 \mathrm{~mm}$ up to UTS $=1200 \mathrm{MPa}$. The VST 55531 alloy is able to provide up to $1600 \mathrm{MPa}$ in sections up to 5 " UTS , and up to $1750 \mathrm{MPa}$ in limited processing of simple sections with certain treatments [2]. This will ensure up to 1.5 times the reduction of the crosssectional area of the part (simplified construction).

Of course, the VST 55531 alloy contains significantly more relatively expensive alloying materials, which increases its cost. In most cases, classical high-strength alloys can be replaced with an economically-doped VST 2 alloy, which includes a large number of waste Ti $6 \mathrm{Al} 4 \mathrm{~V}$, VST 55531, a sponge of low purity and cheaper Fe master alloys [3].

Alloy VST 2 is able to provide up to UTS $<1650 \mathrm{MPa}$ when hardening sections less than $10 \mathrm{~mm}$, UTS $<1450$ MPa when hardening sections less than $50 \mathrm{~mm}$ and UTS $<1170 \mathrm{MPa}$ when annealing sections less than $130 \mathrm{~mm}$. It can also provide a maximum reduction in cross-sectional area (mass) up to 1.35 times.

Increased material fracture toughness increases damage tolerance and can also provide a reduction in the cross-section of the part. So on the alloy VST 55531 can be increased K $1 \mathrm{c}$ material by about 17\% relative to the level of alloy Ti $6 \mathrm{Al} 4 \mathrm{~V}$ with a lamellar structure (Fig. 3)

Conditionally sharing wrought processing on Areas : Equipment development, Stock development, Process development, Material behavior can be characterize .

\section{Equipment development.}

Despite the substantial risks posed by relatively new additive technologies, confidence in the demand for traditional technology remains high. A vivid confirmation of this is the purchase of powerful new press equipment. In Q2 2015, the Nanshan press was commissioned. Forge Company production Siempelkamp Pressen ( Germany ) [ 4 ]. Since the conclusion of the contract, the project has been extended for 3 years. During its creation, Siempelkamp broke its own casting record of 301 tons, making the casting lower press A beam weighing 320 tons. The press has the following parameters:

Force: 50 thousand .T onn (MH 500)

Working stroke speed: $0.05-50 \mathrm{~mm} / \mathrm{s}$

Stroke : $2000 \mathrm{~mm}$

Die clamping area (working table ): $4000 \times 7000 \mathrm{~mm}$

Number of master cylinders: 8, effort $61.3 \mathrm{MN}$ atm )

Hydraulic system : 60 pumps, total power $24 \mathrm{MW}$, volume of hydraulic oil $180 \mathrm{~m} 3$, working pressure 420 bar (428

Open space between columns: 5 × $3 \mathrm{~m}$

Modes of working stroke: compensation of eccentric loads; with control by strain rate; ultra low speed

Dimensions: height $30 \mathrm{~m}$

Weight: 7.5 thousand tons.

In October 2018, an enchanting presentation of the Weber press took place. Metals and OTTO FUCHS KG (US) produced by SMS Meer ( Germany ) [ 5]. The project took just over 2.5 years and cost $\$ 180$ million. This press is considered the most expensive purchased for private investment. Technical options press :

Force: $540 \mathrm{MN}$

Stroke: $2000 \mathrm{~mm}$ (79 In)

Die clamping area: $6000 \times 3000 \mathrm{~mm}$ (236 x 118 in)

Structurally reinforced with four, forged tie rods.

Integrated load-balancing feature

Place: Paramount, Southern California, USA

On VSMPO In the 2nd quarter of 2017, a new complex from the ring rolling mill RAW 400/200-3500/800 and the ring of the blank press with a force of 8,000 tons by the manufacturer SMS Meer ( Germany ) were put into operation .

An important parameter is the forging speed. A relatively simple device that allows you to increase the speed of forging is a forging unit that converts single-axis forging into two axial [7]. To implement this does not require significant retrofitting of the press.

Along with an increase in the forging speed, a sufficient range of movement of the strikers allows for a good development of the structure and a reduction in the probability of cracking due to the reduction of the zone under tensile stresses. Forging with the formation of extrusion zones ( spreading) is an interesting way to increase the one-time degree of deformation. 
By replacing the strikers, the unit can be turned into a universal calibration device with a wide range of calibration dimensions. Even taking into account the drawbacks: limited stroke, initial and final diameters, limited study of large sections (due to the small width of the hammer), at least doubling the required press effort, and as a result limiting the minimum deformation temperature, leave the unit efficient development of equipment.

At the moment, the range of companies using forging blocks is not very large and has 23 companies.

The general increase in the processing efficiency makes it necessary to use complex devices and equipment ensuring maximum form change in a single pass of deformation [8]. The developed tooling consists of 3 embossed rollers with stepped forming protrusions, the combination of the translational and rotational movements of which allows the wall of the pipe billet to be reduced several times in a single pass.

The control surface of the workpiece at a line of production was always relevant, especially with a small semi readout during machining. To control the quality of the bar stock, a shadow scheme was known in which, according to the size of the source shadow light could control the diameter of the rod.

The company Kocks introduced to this technology the measurement of the surface profile using a laser [9] . Laser scanning of the bar surface with a frequency of up to 2000 profiles per second from 4 sides allows you to form a complete surface profile with an accuracy of $\pm 0.025 \mathrm{~mm}$. Of course, at the moment the surface profile obtained with inline scanning with speeds up to $10 \mathrm{~m} / \mathrm{s}$ can not be used to meet the requirements, but at scanning speeds of about $0.5 \mathrm{~m} / \mathrm{s}$, the surface profile turns out to be detailed and quite suitable for assessing requirements .

Hybrid technologies based on additive ones provide quite interesting methods of deformation. As is known, all additive technologies conduct metal through melting, in the case of DMD - multiple, therefore the creation of deformed structures is impossible. However, a method has been proposed for the local deformation by the synthesized surfacing of a wire wall by rolling with a roller, which has a concave profile for relatively thin walls and a convex profile for thick walls [10] . The radius of the bulge may vary. After synthesis, the roller is rolled along the entire surface of the rib. With sufficiently small effort, it is possible to deform the synthesized layer with a degree of deformation sufficient to reduce the b-grain from several millimeters to tens of microns. With increasing degree Defoe $p$ mation by increasing the pressure and number of passes, the grain size used after synthesis is reduced. It should be noted that this technology is relatively easy to scale to thick sections, but the problems of deformation of sections / wall thickness of a few millimeters are obvious .

\section{Stock development}

Solving the problem of tightening the dimensional tolerances while reducing the cross-section of parts like profile, as well as reducing the cross-section of these parts suggested the use of stage processing [ 11 ]. At the first stage, a billet is obtained by high-performance methods, but not allowing to obtain very thin walls with the necessary tolerance. In the second stage, the walls are thinned by rolling to obtain very thin walls with tight tolerances, an increase in BTF, a more uniform deformation over the cross section. In the case of cold rolling it is also possible to use strain hardening.

One of the most relevant areas for the development of a blank is the use of a "hybrid" blank, i.e. obtained by methods of traditional extraction technology [12]. Most common embodiment 3: Synthesis of the preform using conventional powder metallurgical methods of synthesis of the entire workpiece AM, hybrid preform. A hybrid billet consists of a part (more often, a slab) of the traditional technology obtained with the addition of elements to it by methods of additive technology. Additive technologies are understood in the broadest sense. Preparation: powder, wire. A source heating : electronic beam, laser, plasma, electric arc. Powder bed of direct metal depositions.

The preform is subjected Defoe p mation (usually stamping) scheme billet made by conventional method.

It is clear that by hybrid and powder methods it is difficult to obtain a billet of a complex shape, therefore these billets will have a maximum allowance relative to the final geometry. AM the stock will have a minimum allowance. Currently AM synthesis speed even in the case of Hi Depozition Rate ( HDR ) is several times lower than powder and traditional, which causes a longer cycle of preform creation using AM, proportionally increasing the cost of their synthesis. Raw materials in the form of surfacing wire and powder are significantly more expensive than traditional billets, besides powder preforms must be subjected to HIP and follow fur. About processing to remove the container. All of the above casts doubt on the effectiveness of the hybrid billet in terms of cost reduction.

From the point of view of the quality of the material, it is necessary to understand that all the synthesized elements will have a cast structure, respectively, will be subjected to deformation only at the final stage with very small degrees of deformation. This is especially important for layer-by-layer synthesis, in which epitaxial growth of $\beta$ - grains is observed up to a size of several millimeters in the direction of the deposition front [13]. Deformation at $\alpha+\beta$ areas not eliminates given structure . For a relatively equiaxed $\beta$-grains, it is necessary to carry out recrystallization annealing in the $\beta$-region after preliminary deformation with a degree of at least $30-40 \%$ in the $\alpha+\beta$ or $\beta$ region. The need for this $\beta$ - recrystallization annealing also imposes restrictions on the technology of working with a hybrid billet. 
Periodically receives a "new breath" in general traditional hydrogen plasticization technology widely developed around the world in the 70s. Without changing the essence of technology, the areas of the technological cycle of hydrogenation and dehydration are changing. One of the recent proposals is the deflaking during the forging of an ingot into a billet [14] .

When $\mathrm{n}$ eosporimyh advantages in reducing the flow stress and additional features of structure existing high risk of formation of soluble complex hydrides, increase the adsorption kinetics of $\mathrm{H} 2$ in the final semi-finished product, as well as $\mathrm{H} 2$ falling risk in the final product. In addition, the duration of the operation of hydrogenation and dehydration increases with increasing cross-section.

\section{Process development}

Deformation gamma intermetallic compounds is an an important stage in the development of their production, as the most promising high-temperature alloys. The duplex structure of the deformed gamma aluminides provides increased ductility, strength and fatigue strength with an acceptable reduction in heat resistance. The problem is a very high strain resistance, which makes non-isothermal deformation (especially thin sections) very difficult, and leads to the necessity of switching to low strain rates realized in isothermal conditions. The higher metal utilization ratio (CIM) of isothermal punching is balanced by the high costs of the tool and makes it profitable only for mass production. Deformed blades of gamma aluminide are planned to be used in the PW 1100 [ 15 ]

When stamping products of a large projection area, a condition of insufficient pressure of the existing presses occurs. AT by this case applied sectional stamping, with which happens phased registration separate areas . This technology has been used by many companies since the $70 \mathrm{~s}$ and $80 \mathrm{~s}$. In this technology, there are a large number of challenges: defects in the form of clamps and flash, folds of buckling, neoformaniya, which are traditionally solved by trial and error, leading to significant costs during development. A group of authors approached the problem of forming very systemically: a rheological model of the material and structure was constructed, the model was verified, a through iterative simulation of the process of forming was carried out with the identification and elimination of problems, which made it possible to obtain sectional stamping with minimum natural trial work $[16,17]$.

\section{Modeling}

Most intensely developing direction at wrought processing of titanium alloys is a plastic deformation simulation. The most developed and widespread method of modeling is the finite element method. Finit Element Modeling ( FEM ). In recent years, they try to give modeling the status of end-to-end not only by transitions, but also by spheres, adding to modeling plastic deformation, modeling structure and texturing, with the ultimate goal of modeling mechanical properties. The classical FEM plastic deformation modeling based on the rheological data of the alloy currently covers all technologies, allowing you to get the $\mathrm{T}, \varepsilon$, fields on all transitions: forging, stamping, sheet and section rolling, ring rolling. Classical FEM modeling allows simulating the residual stresses during quenching with non-equilibrium conditions [18] .

It also simulates the stress state of the tool to assess its working conditions and durability.

In the classical version of FEM, even under conditions of a complex combination of cooling and adiabatic heating, the accuracy of temperature modeling does not exceed $5^{\circ} \mathrm{C}$ in most cases [19]. The accuracy of modeling geometric dimensions does not exceed 7\% [20]. More difficult is the accuracy of the prediction of the strain effort, since it is very dependent on the parameters of friction and the accuracy of the boundary conditions, but for most simple geometries it does not exceed $15 \%$.

The main direction of the development of modeling is the modeling of microstructure parameters . The most common parameters for $\alpha+\beta$ - alloys are the proportion of the primary $\alpha$-phase , the size of the primary $\alpha$-phase , and the degree of spheroidization.

With a sufficiently significant difference in particular, the modeling process as a whole is structured according to one scheme: conducting an experiment, building a model for the formation of structures, integrating the model for structureforming into the FEM module, and solving boundary value problems.

In work [21] on the alloy $\mathrm{Ti}-6 \mathrm{Al}-2 \mathrm{Zr}-1 \mathrm{Mo}-1 \mathrm{~V}$ an analytical model was used to change the proportion of the primary a-phase $(\gamma \alpha 1)$, the size of the primary a-phase $(\mathrm{b} \alpha 1)$. The verification of the model of structure formation took place in experiment 2 of stage deformation in the range $\mathrm{T}=910-970{ }^{\circ} \mathrm{C}$ with $\varepsilon=50 \%, \dot{\varepsilon}=0.011 / \mathrm{s}$. The solution of the boundaryvalue problem 2 of staged sectional stamping in the package of the commercial package DeForm made it possible to obtain divergence with experiment for $\gamma \alpha 1$ - up to a maximum of $22.2 \%$ on average $9 \%$, for b $\alpha 1-$ to a maximum of $16.7 \%$ on average $8.8 \%$.

In work [22] on the Ti $6 \mathrm{Al} 4 \mathrm{~V}$ alloy, the artificial - neural - network ( ANN ) model of structure formation was carried out on a series of experiments with variation in a wide range of T, $\varepsilon$, $\varepsilon$ deformation, with simulated isothermal exposures . The solution of the boundary-value problem of isothermal punching made it possible to obtain a divergence with experiment for $\gamma \alpha 1<10 \%$, and for non-isothermal $<30 \%$ in some cases, the differences up to 5 times. The divergence with experiment $\mathrm{b} \alpha$ 1 was $<20 \%$.

Significantly smaller difference in level raskhozhde Nia with experimental results operation result [21] with substantially less wide array verification experiment result emphasizes the great strength and stability predictive analytical model 
microstructure . In this case, there always remains the question of monotony and continuity of the function of the magnitude of the error ( discrepancies with experiment ) - are large quantities possible?

In the direction of end-to-end modeling (deformation - struktkura - mech . From the estate), a very ambitious project was launched with the participation of a very representative circle of scientific organizations, consumers, manufacturers of titanium alloys: Rolls-Royce, Boeing, General Electric Aviation, Pratt \& Whitney, Computherm , Cornell University, Scientific Forming Technologies, Materials Resources LLC , PCC - Wyman - Gordon, ATI Forged Products, TIMET, Air Force Research Laboratory [25] . Filled in the form of additional plug-ins to the commercial program DEFORM scheduled model parameters duplex microsructury alloy Ti $6 \mathrm{Al} 4 \mathrm{~V}(\gamma \alpha 1, \mathrm{~b} \alpha 1, \mathrm{~b} \alpha 2$ ) parameters plate strutkury (size $\beta$ grain $\mathrm{D} \beta, \mathrm{b} \alpha 1$, colony size primary $\alpha$-phase $(\mathrm{d} \alpha 1)$ ) crystallographic texture of the primary and secondary $\alpha$-phase , short-term mechanical properties. A colossal work on model verification is planned. The first results show tremendous complexity of this work: modeling of texture secondary $\alpha$-phase koordinalno vary depending on the detail of the grid used. The announced current deviation of model mechanical properties from experimental $\pm 5 \%$ is impressive at first glance. However, the scatter $10 \%$ UTS is approximately $100 \mathrm{MPa}$, which amounts to $28 \%$ of the total range of variation UTS = $1200-850=350 \mathrm{MPa}$ for the alloy Ti $6 \mathrm{Al} 4 \mathrm{~V}$. The minimum acceptable accuracy of the simulation results for using them as reference can be considered $\pm 10 \mathrm{MPa}$, i.e. 5 times lower than the current level. This again indicates a large amount of work ahead.

In a simulated parameter may be not only the parameters of the microstructure, but also any material parameters podver gayuschiesya quantify, for example, ultrasonic (UT) material properties. In [ 23 ], the relationship between the parameters of the ultrasonic signal ( its noise component) and the anisotropy of the $\beta$ - grain of the Ti 6246 alloy was studied experimentally. A model of the ultrasound effect was developed, which is integrated into the FEM module. As a result, developers of the deformation technology have the opportunity to model the ultrasonic properties of the material, which made it possible to optimize them, in cases where other parameters allow it.

At this stage, the microstructural change models work at the post processing stage in the form of private modules. This happens separately from the FEM solver, which takes into account only elasticity, rheology, heat transfer, and special cases of phase transitions ( Stress indused deformation, Transformation plasticity ). In reality, a change in microstructure, texture leads to a change in rheological properties. This should be taken into account in future deformation models in which the model strutkury material ( material models ) will work in the composition or closely solver [3] . Probably, this will make it possible to further clarify the results of modeling shaping and struktkury .

Despite the undeniable advantages that modeling gives about $40 \%$ of forging companies, even classical modeling does not use for very simple reasons: cost and staff qualifications. And their share has not decreased since 2014. This somewhat "cools off" the development of modeling.

\section{Material behavior}

Plastic deformation modeling requires knowledge of the material's response to an external effect. In this case, the classical approach to the description of the deformation behavior is various model approximations of the rheological compression curves. Additional processing of data by the methods proposed by Prasad, YVR allows to reveal the regions of temperature and strain rates in which instability $\backslash$ localization of deformation is possible, which is very important data for combating deformation cracks that are not obtained by other means. An additional analysis of the microstructure of the deformed samples makes it possible to identify areas of structural transformations and obtain a map of the deformation mechanisms [26, 27] . For example, for 6-4, to divide the area of globularization , creasing of plates and adiabatic shear bands, as well as to distinguish the area of grain-boundary cracking. For pseudo- beta alloys, separate the areas of dynamic recrystallization and recovery, and the areas of adiabatic shear bands (localization).

The areas of strain instability in the general case are quite strongly dependent on the degree of deformation, which must be taken into account and taken into account when using [28]. Although it is possible to trace the kinetics of changes in instability areas by the results of some data on the dependence of flow stress on the degree of deformation, simply by analyzing them at different degrees of deformation. More difficult with maps of deformation processes, for which the analysis of structures is necessary, i.e. additional experiment on the deformation to a given degree. This makes the prossesing map analysis relatively versatile.

Processing map@ deformation mechanisms map is very sensitive to changes in the original structure and chemical composition. Reducing oxygen within the alloy grade 6-4 from 0.18 to 0.13 significantly and increasing the thickness of the plates of the primary a-phase by about 2 times, the maximum temperatures of the prior b-boundary cracking and adiabatic shear bands decrease from 900 to $800^{\circ} \mathrm{C}$, and The limiting deformation rate ensuring the spheroidization of the $\alpha$ phase grows by an order of magnitude from 10-2 to 10-1 [26, 29]. In this case, the question remains open about the accuracy of determining these areas.

One of the drawbacks of processing maps is the unknown accuracy of the calculation of the energy dissipation efficiency (nu) and the range of flow instability ( $\mathrm{k}$ or e) [27] . Being within the same approximation, slightly different ways of calculating nu and $\mathrm{k}$ give them a very significant change. In practical terms, this complicates the process of choosing the optimal deformation mode.

Another limitation is that even deformation in an area free from localization and grain boundary cracking can lead to the formation of deformation defects, primarily on the surface. This speaks first of all about the existence of additional 
important factors, which do not take into account this approximation.

Despite the large amount of research and data on the deformation behavior (rheology) and the evolution of the microstructure during the deformation process, very little attention has been paid to the effect of stops / interruptions during deformation on the deformation behavior. In recent works [30], it was shown that at holding up to $10 \min$ in the $\mathrm{a}+\mathrm{b}$ region with large strains $(>0.4)$ does not lead to significant softening, and repeated loading does not lead to restrengthening above the level before the interruption.

In the region of small deformations in tension, no significant changes in the flow stress after interruption $[31,32]$ are also observed, despite the fact that the stress relaxation significantly increased with increasing temperature.

\section{Conclusion}

The paper examines the main development trends of wrought processing of titanium alloys. Despite the high level of development and mastering of the main methods and directions in wrought processing, there remain enough areas of development and optimization of which gives tangible practical results.

\section{$\underline{\text { References }}$}

[1]. 2014-2018 FORGING BUSINESS OUTLOOK, https://www.forgingmagazine.com/

[2]. Технический отчет. Неопубликованная работа.

[3]. Leder M.O., Tetyuhin V.V., Volkov A.V., et al. Adapted-Alloyed High-Strength VST2 Alloy: Structure, Properties.

AEROMAT 2017, Charleston, South Carolina, April, 2017

[4]. http://www.nanshanforge.com, https://www.siempelkamp.com

[5]. https://www.otto-fuchs.com/en/business-areas/aerospace-industry/asg-group-60k.html

[6]. https://www.vsmpo.ru

[7]. D.Lazorkin. High performance thechnology and equpment ..., ITA2018

[8]. Wang, X.X., Zhan, M., Fu, M.W., Gao, P.F., Guo, J., Ma, F., 2018. Microstructure evolution of Ti-6Al-2Zr-1Mo-1V alloy and its mechanism in multi-pass flow forming. Journal of Materials Processing Technology 261, 86-97. df

[9]. Glyn Ellis, 4D eagle: the new gauge from Kocks for bar and wire rod quality assurance, Titanium USA 2017

[10]. McAndrew, A.R., Alvarez Rosales, M., Colegrove, P.A., et al, 2018. Interpass rolling of Ti-6Al-4V wire + arc additively manufactured features for microstructural refinement. Additive Manufacturing 21, 340-349.

[11]. US 2017 / 0306467 A1 Oct.26, 2017

[12]. US 2015/0013144 A1 Jan. 15, 2015

[13]. Semiatin, S.L., Kobryn, P.A., et al., 2001. Plastic flow and microstructure evolution during thermomechanical processing of laser-deposited Ti-6Al-4V preforms. Metallurgical and Materials Transactions A 32, 1801-1811.

[14]. US 2018 / 0347003 A1 Dec . 6, 2018

[15]. Smarsly, W., 2016. Status of Titanium Aluminide for Aero Engine Applications, Titanium Europe 2016, Paris, France.

[16]. Zhang, D.-W., Fan, X.-G., 2018. Review on intermittent local loading forming of large-size complicated component: deformation characteristics. The International Journal of Advanced Manufacturing Technology 99, 1427-1448.

[17]. Fan, X.G., Yang, H., Gao, P.F., 2014. Through-process macro-micro finite element modeling of local loading forming of large-scale complex titanium alloy component for microstructure prediction. Journal of Materials Processing Technology 214, 253-266. ап

[18]. de Oliveira, M., Ward, J., Garwood, D.R., Wallis, R.A., 2002 Quenching of aerospace forgings from high temperatures using air-assisted, atomized water sprays. Journal of Materials Engineering and Performance 6., 11, 80-85.

[19]. Venkatesh, V., Wilson, A., Kamal, M., Thomas, M., Lambert, D., 2009. Computational modeling in the primary processing of titanium: A review. JOM 61, 45-50.

[20]. Fan, X.G., Yang, H., Gao, P.F., 2014. Through-process macro-micro finite element modeling of local loading forming of large-scale complex titanium alloy component for microstructure prediction. Journal of Materials Processing Technology 214, 253-266.

[21]. Fan, X.G., Yang, H., Gao, P.F., 2014. Through-process macro-micro finite element modeling of local loading forming of large-scale complex titanium alloy component for microstructure prediction. Journal of Materials Processing Technology 214, 253-266.

[22]. Kim, J.H., Reddy, N.S., Yeom, J.T., Hong, J.K., Lee, C.S., Park, N.-K., 2009. Microstructure prediction of two-phase titanium alloy during hot forging using artificial neural networks and FE simulation. Metals and Materials International 15, 427-437.

[23]. Y. Ito, H. Takamatsu, K. Kinoshita, and K. Steel, 2015, 'Technologies for reliable titanium alloy forgings focusing on ultrasonic inspection in aerospace industry',TiUSA2015.

[24]. Salem, A.A., Shaffer, J.B., Satko, D.P., Semiatin, S.L., Kalidindi, S.R., 2014. Workflow for integrating mesoscale heterogeneities in materials structure with process simulation of titanium alloys. Integrating Materials and Manufacturing Innovation 3.

[25]. M.G. Glavicic, T. Morton1, T. Broderick et al, 2016, PROGRESS IN THE ADVANCED TITANIUM MICROSTRUCTURE AND MODELING PROGRAM, Proceedings of the 13th World Conference on Titanium, 1867-1873

[26]. Seshacharyulu, T., Medeiros, S.C., Frazier, W.G., Prasad, Y.V.R.K., 2002. Microstructural mechanisms during hot 
working of commercial grade Ti-6Al-4V with lamellar starting structure. Materials Science and Engineering: A 325, 112125.

[27]. Dikovits, M., Poletti, C., Warchomicka, F., 2014. Deformation Mechanisms in the Near- $\beta$ Titanium Alloy Ti-55531. Metallurgical and Materials Transactions A 45, 1586-1596.

[28]. Nie, X., Hu, Z., Liu, H., Yi, D., et. al. 2014. High temperature deformation and creep behavior of Ti-5Al-5Mo-5V$1 \mathrm{Fe}-1 \mathrm{Cr}$ alloy. Materials Science and Engineering: A 613, 306-316.

[29]. Tamirisakandala, S., Medeiros, S.C., Frazier, W.G., Prasad, Y.V.R, 2001. Strain-Induced Porosity during Cogging of Extra-Low Interstitial Grade Ti-6Al-4V. Journal of Materials Engineering and Performance 10, 125-130.

[30]. X. G. Fan, H. Yang, P. F. Gao. Deformation behavior and microstructure evolution in multistage hot working of TA15 titanium alloy: on the role of recrystallization, J Mater Sci (2011) 46:6018-6028 sdf

[31]. R. Julien, V. Velay, V. Vidal, Y. Dahan, R. Forestier, F. Rézaï-Aria, Tensile behaviour of high temperature forged Ti6Al-4V during in-situ heat treatments, Materials Letters (2017)

[32]. R. Julien, V. Velay, V. Vidal, Y. Dahan, R. Forestier, F. R«eza $\neg$ õ-Aria,Characterization and modeling of forged Ti6Al-4V Titanium alloy with microstructural consid-erations during quenching process, International Journal of Mechanical Sciences (2018), 